\title{
Hepatitis $B$ virus reactivation or reinfection in a FEM-PrEP participant: a case report
}

Mookho Malahleha ${ }^{\text {* }}$, Khatija Ahmed ${ }^{1}$, Jennifer Deese ${ }^{2}$, Kavita Nanda², Lut van Damme ${ }^{3}$, Irith De Baetselier ${ }^{4}$ and Rosemary J. Burnett ${ }^{5}$

\begin{abstract}
Introduction: The FEM-PrEP trial was a pre-exposure prophylaxis clinical trial to test the safety and efficacy of Truvada (tenofovir disoproxil fumarate and emtricitabine) in the prevention of human immunodeficiency virus infection. Because Truvada can suppress hepatitis B virus replication, and withdrawal of Truvada can cause hepatic flares in patients with chronic hepatitis B, pre-enrollment screening included serological screening for hepatitis B virus markers. Women with chronic infections were not enrolled in the trial. Women found to be unprotected against hepatitis B were enrolled and offered three doses of hepatitis B vaccine. Reinfection and reactivation of previously resolved hepatitis $B$ virus infections have been documented in immunosuppressed individuals but not in healthy individuals. We present the case of a participant enrolled in the FEM-PrEP clinical trial with baseline evidence of immunity against hepatitis B virus who subsequently developed acute hepatitis B.

Case presentation: A 21-year-old Black non-pregnant woman was enrolled in the FEM-PrEP trial. She was human immunodeficiency virus-negative and a serological test for hepatitis B virus was negative. She had evidence of low levels of protection against hepatitis B virus and normal liver function. She had no hepatitis B vaccination history, thus it was concluded that she had post-infection immunity. At week 36 she presented with severely elevated liver enzyme levels that, upon further investigation, were a result of acute hepatitis B virus infection. The infection followed an asymptomatic course until full recovery of her liver enzymes a few weeks later. At study unblinding, the participant was found to be on the Truvada arm. Retrospective plasma drug level testing found low levels of study drugs from week 4. The participant remained human immunodeficiency virus-negative throughout the study.

Conclusion: Hepatitis B virus infection reactivation or reinfection is a rare phenomenon in healthy individuals. However, reactivations have been reported in patients being treated for chronic hepatitis B with the drugs contained in Truvada, after treatment had been withdrawn. This participant may have reactivated after stopping Truvada, or she may have reactivated spontaneously owing to relatively low levels of protective antibodies against hepatitis B. Alternatively, she may have been reinfected. Clinicians should be aware that hepatitis B virus reactivation or reinfection may cause elevated transaminases even in the presence of low baseline immunity.
\end{abstract}

Keywords: FEM-PrEP, Hepatitis B virus, Reactivation, Reinfection

\section{Introduction}

The FEM-PrEP clinical trial was a randomized, blinded, placebo-controlled trial of daily oral Truvada $300 \mathrm{mg}$ tenofovir disoproxil fumarate [TDF] and $200 \mathrm{mg}$ emtricitabine [FTC]) for the prevention of human immunodeficiency virus (HIV) infection in women, conducted in Kenya, South Africa, and Tanzania, from 2009 to 2011.

\footnotetext{
* Correspondence: mookho@setshaba.org.za

${ }^{1}$ Setshaba Research Centre, 2088 Block H, Soshanguve, Pretoria 0152, South Africa

Full list of author information is available at the end of the article
}

The primary objectives were to assess the efficacy and safety of daily oral Truvada among HIV-negative women at high risk for HIV infection. Assessments included pregnancy and HIV testing every 4 weeks, and monitoring of renal and hepatic function (alanine aminotransferase [ALT] and aspartate aminotransferase [AST]) at weeks 4 and 12, and then quarterly for up to 52 weeks. Toxicity was graded according to the Division of AIDS grading scale [1], and was managed as per protocol. Because both TDF and FTC suppress hepatitis B virus (HBV) replication, and withdrawal of these products can 
cause hepatic flares in patients with chronic hepatitis B (HB), pre-enrollment screening included testing for $\mathrm{HB}$ surface antigen ( $\mathrm{HBsAg}$ ) and antibodies to $\mathrm{HBsAg}$ (anti-HBs). Anti-HBs titers between 8.0IU/L and $12.0 \mathrm{IU} / \mathrm{L}$ were retested in duplicate. If both repeat tests were $\geq 10 \mathrm{IU} / \mathrm{mL}$, the sample was considered reactive. HBsAg-positive women were not enrolled, while enrolled anti-HBs-negative participants (that is, with antiHBs <10IU/L) were offered three doses of HB vaccine. HBsAg testing was repeated at the time of product withdrawal in participants who did not complete the $H B$ vaccination series or refused vaccination, to assess potential risk of hepatic flare. Study procedures and the main results have been described elsewhere [2].

\section{Case presentation}

A 21-year-old, Black, non-pregnant woman with normal liver function (baseline ALT 22IU/L and AST 34IU/L) was enrolled in the FEM-PrEP trial in August 2009. She was HIV-negative, HBsAg-negative, and anti-HBs-positive (11.19IU/L initially; confirmatory tests, $11.12 \mathrm{IU} / \mathrm{L}$ and $11.05 \mathrm{IU} / \mathrm{L})$. She was not offered $\mathrm{HB}$ vaccination because her anti-HBs level was greater than 10IU/L. She had no HB vaccination history, thus it was concluded that she had post-infection immunity.

Her study visits up to follow-up week 32 were uneventful and her liver function test results at weeks 4 , 12 , and 24 were normal. At week 36 , she was well with no clinical findings, but had grade 1 hepatotoxicity (ALT 48IU/L; AST 59IU/L), which progressed to grade 2 toxicity (ALT 117IU/L; AST 95IU/L) at week 40. She reported no concomitant use of medications, herbals, injectable drugs, or alcohol.

At week 44, she remained asymptomatic despite grade 4 hepatotoxicity (ALT 1,094IU/L; AST 517IU/L). She returned 5 days later (following multiple contact attempts) at which time the study drug was permanently withdrawn. She remained HIV-negative, was clinically well with no signs of liver disease, and continued to deny concomitant medication or substance use, or recent travel. However, the grade 4 hepatotoxicity (ALT 1,887IU/L; AST 1,358IU/L) persisted at that visit, and she was found to have significantly elevated levels of lactate dehydrogenase phosphate (LDP, 1298IU/L) and gamma-glutamyl transpeptide (GGT, 433IU/L) in the presence of normal (68IU/L) alkaline phosphatase levels. Her total bilirubin $(38 \mu \mathrm{mol} / \mathrm{L})$ and direct bilirubin $(20 \mu \mathrm{mol} / \mathrm{L})$ levels were also elevated. Hepatitis C virus, hepatitis A virus, Epstein-Barr virus and cytomegalovirus tests were negative, but tests for HBsAg, $\mathrm{HB}$ e antigen (HBeAg), anti-HBs (11.92IU/L), and total and immunoglobulin $\mathrm{M}$ (IgM) HB core antibodies (anti-HBc) were positive.
The participant failed to return to the clinic until week 48. She remained HIV-negative, and her liver function test results showed decreases in ALT to grade 2 hepatotoxicity $(119 \mathrm{IU} / \mathrm{L}) ; \mathrm{AST}$ to grade $1(41 \mathrm{IU} / \mathrm{L}) ; \mathrm{LDP}$ to 485IU/L; and GGT to $178 \mathrm{IU} / \mathrm{L}$. She remained positive for HBsAg, total anti-HBc, IgM anti-HBc, and anti-HBs (11.3IU/L), but was HBeAg-negative. Her HBV viral load (VL) at this visit was $87 \mathrm{copies} / \mathrm{mL}$.

At week 52, the participant was well, with normal ALT, AST, LDP, and alkaline phosphatase levels and slightly elevated GGT (49IU/L). She was HBsAg-negative, anti-HBspositive (11.29IU/L), and had an HBV VL of 40 copies/ $\mathrm{mL}$. The HBV infection was determined to have almost resolved, with full recovery of liver function. At week 56, her ALT and AST remained normal (26 and 16IU/L respectively). She remained HIV-negative and completed study participation at week 60. In September 2012, anti$\mathrm{HBC}$ and HBV DNA were assessed retrospectively on stored specimens from her screening visit to exclude occult HBV infection at enrollment. The samples were anti-HBc negative, and HBV-DNA was undetectable. An anti-HBs test on the stored sample was negative.

At study unblinding, this participant was identified as having been in the Truvada arm. Retrospective plasma drug level testing found low levels of TDF $(1.7 \mathrm{ng} / \mathrm{mL})$ and FTC $(1.0 \mathrm{ng} / \mathrm{mL})$ at week 4 and undetectable levels in all subsequent weeks. All results have been summarized in Table 1.

\section{Discussion}

Increased levels of liver transaminases indicate hepatocellular injury and can have many causes, including alcohol use, drug use (including toxicity due to therapeutic drugs or herbal remedies), autoimmune diseases, and viral infections including acute HIV [3]. In this case, the participant reported no history of alcohol use and no concomitant medications or herbal remedies, and remained HIV-negative throughout the study. Although both TDF and FTC can result in hepatotoxicity [4], and this participant received Truvada, she exhibited poor study drug adherence with undetectable plasma drug levels from study week 12 until product withdrawal; therefore, it is unlikely that her raised transaminases were a result of Truvada toxicity. The cause of her severely elevated liver transaminases was determined to be HBV infection based on a hepatitis screening test.

In sub-Saharan Africa, most acute HBV infections are asymptomatic, being acquired by the age of 5 years through horizontal transmission among toddlers [5]. The majority of these infections result in chronic $\mathrm{HB}$, with the host immune response confined to anti-HBc, which are usually detectable lifelong, and unable to clear HBsAg. Acute infections acquired later in life, primarily through sexual transmission, typically cause symptomatic illness 
Table 1 Summary of results

\begin{tabular}{|c|c|c|c|c|c|c|}
\hline & Date & $\mathrm{ALT}(\mathrm{IU} / \mathrm{L})$ & AST (IU/L) & Hepatitis screen & Other tests (normal range) & Comment \\
\hline \multirow[t]{2}{*}{ Screening } & \multirow[t]{2}{*}{$13 / 08 / 2009$} & \multirow[t]{2}{*}{22} & \multirow[t]{2}{*}{34} & \multicolumn{2}{|l|}{$\mathrm{HBsAg}=$ Negative } & \\
\hline & & & & \multicolumn{2}{|l|}{$\mathrm{HBsAb}=$ Positive HBsAb Value $=11.19 \mathrm{IU} / \mathrm{L}$} & \\
\hline RFU Wk $4^{a}$ & 21/09/2009 & 17 & 22 & - & - & \\
\hline RFU Wk 12 & $16 / 11 / 2009$ & 32 & 31 & - & - & \\
\hline RFU Wk 24 & $09 / 02 / 2010$ & 19 & 27 & - & - & \\
\hline RFU Wk 36 & 07/05/2010 & 48 & 59 & - & - & Grade $1^{\text {a }}$ \\
\hline RFU Wk 40 & $02 / 06 / 2010$ & 117 & 95 & - & - & Grade 2 \\
\hline RFU Wk 44 & 02/07/2010 & 1094 & 517 & - & - & Grade 4 \\
\hline \multirow[t]{7}{*}{ Unscheduled visit } & 09/07/2010 & 1,887 & 1,358 & $\mathrm{HBsAg}=$ Positive & $\mathrm{LDP}=1,298 \mid \mathrm{U} / \mathrm{L}(200-500)$ & Diagnosis: Acute Hepatitis B \\
\hline & \multirow[t]{6}{*}{ Permanent product withdrawal } & & & $\mathrm{HBeAg}=$ Positive & $\mathrm{GGT}=433 \mathrm{IU} / \mathrm{L}(0-35)$ & \\
\hline & & & & $\mathrm{HBC} \lg M=$ Positive & $A L P=68 I U / L(40-120)$ & \\
\hline & & & & $\mathrm{HBsAb}=$ Positive & Total bilirubin $=38 \mu \mathrm{mol} / \mathrm{L}(0-21)$ & \\
\hline & & & & $\mathrm{HBsAb}=11.921 \mathrm{U} / \mathrm{L}$ & Direct bilirubin $=20 \mu \mathrm{mol} / \mathrm{L}(0-7)$ & \\
\hline & & & & $\mathrm{HCV} \lg \mathrm{M}=$ Negative & Epstein-Barr virus $\lg M=$ Negative & \\
\hline & & & & HAV IgM = Negative & Cytomegalovirus $\lg M=$ Negative & \\
\hline \multirow[t]{7}{*}{ RFU Wk 48} & \multirow[t]{7}{*}{$26 / 07 / 2010$} & \multirow[t]{7}{*}{109} & \multirow[t]{7}{*}{41} & $\mathrm{HBsAg}=$ Positive & $\mathrm{LDP}=485 \mathrm{IU} / \mathrm{L}$ & \multirow[t]{7}{*}{ Grade 2} \\
\hline & & & & $\mathrm{HBeAg}=$ Negative & & \\
\hline & & & & $\mathrm{HBC} \lg \mathrm{M}=$ Positive & $\mathrm{GGT}=178 \mathrm{U} / \mathrm{L}$ & \\
\hline & & & & $\mathrm{HBsAb}=11.39 \mathrm{IU} / \mathrm{L}$ & $A L P=41 I U / L$ & \\
\hline & & & & $\mathrm{HBCAb}=$ Positive & Total bilirubin $=15 \mu \mathrm{mol} / \mathrm{L}$ & \\
\hline & & & & \multirow[t]{2}{*}{$\mathrm{HBV} V L=87 \mathrm{cp} / \mathrm{mL}$} & Direct bilirubin $=3.6 \mu \mathrm{mol} / \mathrm{L}$ & \\
\hline & & & & & International normalized ratio $=1.1$ & \\
\hline \multirow[t]{3}{*}{ RFU Wk 52} & \multirow[t]{3}{*}{$23 / 08 / 2010$} & \multirow[t]{3}{*}{23} & \multirow[t]{3}{*}{12} & $\mathrm{HBsAg}=$ Negative & $\mathrm{LDP}=484 \mid \mathrm{U} / \mathrm{L}$ & \multirow[t]{3}{*}{ Resolution of hepatitis B infection } \\
\hline & & & & $\mathrm{HBV} V \mathrm{~L}=40 \mathrm{cp} / \mathrm{mL}$ & $\mathrm{GGT}=49 \mathrm{IU} / \mathrm{L}$ & \\
\hline & & & & $\mathrm{HBsAb}=11.29 \mathrm{IU} / \mathrm{L}$ & $A L P=36 \mid U / L$ & \\
\hline RFU Wk 56 & 20/09/2010 & 22 & 12 & - & - & \\
\hline Stored screening sample & $12 / 09 / 2012$ & - & - & HBV-DNA PCR: Undetectable & - & Exclusion of occult Hepatitis B \\
\hline
\end{tabular}

$\overline{A L T}$ alanine aminotransferase, $A L P$ alkaline phosphatase, $A S T$ aspartate aminotransferase, GGT gamma-glutamyl transpeptide, $H B V$ hepatitis $B$ virus, $H B C A b$ hepatitis $B$ core antibodies, $H B E A g$ hepatitis B e antigen, $H B s A g$ hepatitis B surface antigen, HCV hepatitis VC virus, IgM immunoglobulin $\mathrm{M}, L D P$ lactate dehydrogenase

phosphatase, PCR polymerase chain reaction; RFU Wk Regular follow-up week, VL viral load 
cleared by neutralizing anti-HBs, followed by lifelong immunity [6]. Anti-HBs is also elicited by the HB vaccine, and those who have mounted a sufficient $(\geq 10 \mathrm{IU} / \mathrm{L})$ antiHBs response to either the vaccine or natural infection are assumed to have lifelong protection, even if the titers wane over time [6]. Seropositivity for anti-HBs in the absence of other serological markers usually denotes immunity owing to $\mathrm{HB}$ vaccination. However, reports exist of natural infection where anti-HBc has disappeared before anti-HBs [7], and anti-HBs alone has previously been found in healthy South African individuals with no history of HB vaccination but with occult HBV infection [8].

The participant in this case had not been vaccinated and had consistent low levels of anti-HBs at baseline and throughout the trial, even in the presence of acute HBV infection. Retrospective testing (in September 2012) of her baseline specimen found no anti-HBc or HBV DNA; however, a repeat anti-HBs test was negative after having been repeatedly positive at the time of pre-enrollment, suggesting possible degradation of the specimen during storage, thus these results may not be reliable. It is also possible that HBV DNA may have been present in her liver, but this could not be ascertained. The "anti-HBs alone" finding with no vaccination history suggests that the participant may have been infected at an early age and experienced waning anti-HBc over time. Thus, possible explanations for her clinical course include either reactivation of a past HBV infection or reinfection. The only way to differentiate between reactivation and reinfection would be by a comparison of HBV genome sequences at baseline versus follow-up; however, sequencing was not possible in this case because HBV DNA was not detected at baseline [9].

HBV reactivations and reinfections are usually associated with immunosuppression, such as that found in HIV infection [5]. However, this participant remained HIV-negative throughout study participation. HBV reactivation has also been reported in a patient being treated for chronic HB after withdrawal of TDF [10], and in patients with HIV infection on antiretroviral treatment after the withdrawal of TDF [11] and TDF/ FTC [12]. It is therefore possible that the discontinuation of Truvada by the participant between weeks 4 and 12 could have resulted in HBV reactivation.

\section{Conclusions}

HBV reinfection or reactivation is a rare phenomenon in healthy individuals. In this case, the trial participant may have reactivated after stopping Truvada use, or she may have reactivated spontaneously owing to relatively low anti-HBs levels. Alternatively, she may have been reinfected with HBV. Clinicians should be aware that HBV reactivation or reinfection may cause elevated transaminases even in the presence of low baseline immunity.

\section{Consent}

Written informed consent was obtained from the patient giving permission for study data to be published. A copy of the written consent is available for review by the Editor-in-Chief of this journal.

\section{Competing interests}

The authors declare that they have no competing interests.

\section{Authors' contributions}

MM was involved in data collection, analysis, and interpretation and writing of the manuscript. KA assisted in data analysis and interpretation and contributed to the writing of the manuscript. RB was instrumental in data interpretation and the writing of the manuscript. ID facilitated additional investigations and contributed to the analysis. KN, LVD, and JD contributed to data analysis and interpretation and writing of the manuscript. All authors read and approved the final manuscript.

\section{Acknowledgements}

FEM-PrEP was conducted under two projects funded by the United States Agency for International Development (USAID): first, the Contraceptive and Reproductive Health Technologies and Research Utilization Program, and then the Preventive Technologies Agreement No. GHO A 0009 00016-00. Early support was also provided by the Bill \& Melinda Gates Foundation. Gilead Sciences, Inc. donated the study pills.

\section{Author details}

'Setshaba Research Centre, 2088 Block H, Soshanguve, Pretoria 0152, South Africa. ${ }^{2}$ FHI 360, 359 Blackwell Street, Suite 200, Durham, NC 27701, USA. ${ }^{3}$ Bill and Melinda Gates Foundation, 500 Fifth Avenue North, Seattle, WA 98109, USA. ${ }^{4}$ Institute of Tropical Medicine, Nationalestraat 155, Antwerpen 2000, Belgium. ${ }^{5} \mathrm{HIV}$ and Hepatitis Research Unit, Department of Virology, University of Limpopo, Medunsa Campus, PO Box 173, Medunsa, Pretoria 0204, South Africa.

Received: 7 January 2015 Accepted: 18 August 2015

Published online: 28 September 2015

\section{References}

1. National Institute of Allergy and Infectious Diseases. Division of AIDS Table for Grading the Severity of Adult and Pediatric Adverse Events. 2004. http://www.niaid.nih.gov/LabsAndResources/resources/ DAIDSClinRsrch/Documents/daidsaegradingtable.pdf. Accessed 18 August 2014.

2. Van Damme L, Corneli A, Ahmed K, Agot K, Lombaard J, Kapiga S, et al. Preexposure prophylaxis for HIV infection among African women. N Engl J Med. 2012;367(5):411-22.

3. Limdi JK, Hyde GM. Evaluation of abnormal liver function tests. Postgrad Med J. 2003;79(932):307-12.

4. Truvada. Highlights of prescribing information. http://www.gilead.com/ /media/Files/pdfs/medicines/hiv/truvada/truvada_pi.PDF. Accessed 18 August 2014.

5. Burnett RJ, François G, Kew MC, Leroux-Roels G, Meheus A, Hoosen AA, et al. Hepatitis $B$ virus and human immunodeficiency virus co-infection in sub-Saharan Africa: a call for further investigation. Liver Int. 2005;25(2):201-13.

6. World Health Organization. Hepatitis B vaccines. WHO position paper. Wkly Epidemiol Rec. 2009;40(84):405-20.

7. Gerlich WH, Wend UC, Glebe D. Gaps in the diagnosis and prevention of hepatitis B virus infection. South Afr J Epidemiol Infect. 2008;23:38-9.

8. Owiredu WK, Kramvis A, Kew MC. Hepatitis B virus DNA in serum of healthy black African adults positive for hepatitis B surface antibody alone: possible association with recombination between genotypes A and D. J Med Virol. 2001;64(4):441-54

9. Costantini A, Marinelli K, Biagioni G, Monachetti A, Ferreri ML, Butini L, et al. Molecular analysis of hepatitis B virus (HBV) in an HIV co-infected patient 
with reactivation of occult HBV infection following discontinuation of lamivudine-including antiretroviral therapy. BMC Infect Dis. 2011;11:310.

10. Schildgen $\mathrm{O}$, Hartmann $\mathrm{H}$, Gerlich WH. Replacement of tenofovir with adefovir may result in reactivation of hepatitis B virus replication. Scand J Gastroenterol. 2006;41(2):245-6.

11. van Bömmel F, Berg T. Reactivation of viral replication after replacement of tenofovir by adefovir. Hepatology. 2005;42(1):239-40.

12. Seang $\mathrm{S}$, Thibault V, Valantin MA, Katlama C. Adjustment of antiretroviral regimen may lead to HBV reactivation even in patients with past HBV infection serological profile. J Infect Chemother. 2013;19(5):987-9.

\section{Submit your next manuscript to BioMed Central} and take full advantage of:

- Convenient online submission

- Thorough peer review

- No space constraints or color figure charges

- Immediate publication on acceptance

- Inclusion in PubMed, CAS, Scopus and Google Scholar

- Research which is freely available for redistribution 